\title{
Analisis Redaman pada Jaringan Fiber to the Home (FTTH) Berteknologi Gigabit Passive Optical Network (GPON) di PT Telkom Makassar
}

\author{
Andi Nurul Ulfawaty $Z^{* 1}$, Fausiah ${ }^{2}$ \\ ${ }^{1,2}$ Program Studi Teknik Elektro Universitas Muhammadiyah Makassar \\ e-mail: anulfa25@gmail.com
}

\begin{abstract}
The development of telecommunications technology as a communication necessity at this time has been growing rapidly, needed a means of transmission media that is able to distribute information with large capacity and capable data transfer speeds. Implementing using Gigabit Passive Optical Network (GPON) technology, the Fiber to The Home (FTTH) service reaches the user to meet the speed of 2GBps. This study aims to identify the causes of increased attenuation or disturbance in FTTH. The method used in this study is to analyze the attenuation value of each core at the sites studied on the FTTH network at PT Telkom. The total attenuation value of fiber optic cables that are calculated from OLT to ONT must be within the specified reasonable limit of 15-28 dB. The caused of the increase in the attenuation value of fiber optic cables such as the number of splice / connections on each cable, and the occurrence of cable indentations above $45^{\circ}$. To overcome the attenuation value that exceeds the reasonable limit can be done by replacing the fiber cable with attenuation of $0.35 \mathrm{~dB}$ to fiber cable with attenuation of $0.22 \mathrm{~dB}$, so that the attenuation of the fiber optic cable is at the specified reasonable limit.
\end{abstract}

Keyword: Optical Fiber; FTTH; GPON; Attenuation; Transmission

\begin{abstract}
Abstrak
Perkembangan teknologi Telekomunikasi sebagai kebutuhan berkomunikasi saat ini telah berkembang dengan pesatnya, dibutuhkan sarana media transmisi yang mampu menyalurkan informasi dengan kapasitas besar dan kecepatan transfer data yang memumpuni. dengan menerapkan teknologi Gigabit Passive Optical Network (GPON) maka layanan Fiber to The Home (FTTH) sampai ke user hingga memenuhi kecepatan 2GBps. Penelitian ini bertujuan untuk mengidentifikasi penyebab terjadinya peningkatan redaman atau gangguan pada FTTH. Metode yang digunakan pada penelitian ini yaitu dengan menganalisis nilai redaman tiap core pada site-site yang diteliti pada jaringan FTTH di PT Telkom. Nilai Redaman total pada kabel Fiber Optik yang terhitung mulai dari OLT sampai ONT harus berada pada batas wajar yang telah ditentukan yaitu 15-28 dB. Penyebab terjadinya peningkatan nilai redaman pada kabel fiber optik seperti banyaknya splice/sambungan pada setiap kabel, dan terjadinya lekukan kabel di atas $45^{\circ}$. Untuk mengatasi nilai redaman yang melewati batas wajar dapat dilakukan dengan mengganti kabel fiber dengan redaman $0,35 \mathrm{~dB}$ menjadi kabel fiber dengan redaman $0,22 \mathrm{~dB}$, agar redaman pada kabel fiber optik berada pada batas wajar yang ditentukan.
\end{abstract}

Kata kunci: Fiber Optik; FTTH; GPON; Redaman; Transmisi

\section{Pendahuluan}

Perkembangan teknologi Telekomunikasi sebagai kebutuhan berkomunikasi saat ini telah berkembang dengan pesatnya. Pada perkembangan telekomunikasi yang pesat ini, dibutuhkan sarana media transmisi yang mampu menyalurkan informasi dengan kapasitas besar dan kecepatan transfer data yang memumpuni. Pada perkembangan teknologi komunikasi ini dibutuhkan media transmisi yang memumpuni dari segi kapasitas maupun kecepatan transfer data.

Serat Optik adalah salah satu media transmisi yang memiliki kapasitas informasi yang besar dan memilki kecepatan transfer informasi yang memumpuni. Teknologi penggunaan 
kabel serat optik sebagai media transmisi dalam sistem telekomunikasi disebut sebagai JARLOKAF (Jaringan Lokal Akses Fiber). JARLOKAF menawarkan kecepatan transfer data lebih cepat. Salah satu perkembangan JARLOKAF yaitu FTTH. Jika dibandingkan dengan kabel tembaga yang bisa mengangkut data sampai 1,5Mbps untuk jarak dekat (kurang dari 2,5 $\mathrm{km}$ ), kabel serat optik bisa mengangkut data hingga 2,5Gbps untuk jarak yang lebih jauh (200 $\mathrm{km}$ ) artinya dengan jarak 80 kali lebih panjang, kabel serat optik mampu mengangkut data lebih dari 1.500 kali kemampuan kabel tembaga.

GPON merupakan salah satu teknologi jaringan serat optik pasif. GPON merupakan teknologi yang dipilih oleh PT Telkom tbk untuk menanggulangi jaringan FTTH. Teknologi GPON sudah mendukung aplikasi triple play, Pada perancangan konfigurasi FTTH, para pegguna jaringan ini sering mengalami peningkatan redaman. Gangguan tersebut biasa terjadi karena adanya peningkatan nilai redaman yang melewati batas wajar redaman yang ditentukan yaitu maksimal $28 \mathrm{~dB}$.

\section{Metode Penelitian}

Redaman merupakan sifat yang paling penting dari sebuah serat optik. Mekanisme distorsi dalam serat memperluas sinyal optik saat pentransmisian sepanjang serat. Jika sinyal ini perjalanannya cukup jauh, akhirnya akan tumpang tindih dengan pulsa tetangga, sehingga menciptakan kesalahan di penerima output, Mekanisme distorsi sinyal membatasi kapasitas informasi pembawa dari serat. Selain redaman pada transmisi serat optik ini terjadi juga dispersi. Dispersi pada akhirnya akan mengakibatkan pulsa-pulsa optik saling tumpang tindih satu dengan yang lain, dikarenakan pulsa-pulsa cahaya memuai dan menjadi lebih lebar. Batas wajar redaman total mulai dari STO hingga ke pengguna yaitu 15-28 dB, jika melewati batas wajar redaman maka terjadi gangguan pada jaringan FTTH tersebut.

OTDR atau Optical Time Domain Reflection merupakan alat yang digunakan untuk mengevaluasi suatu serat optik pada domain waktu. OTDR dapat menganalisis setiap dari jarak akan insertion loss, reflection dan rugi-rugi yang muncul pada setiap titik, serta dapat menampilkan informasi pada layar tampilan. Prinsip kerja OTDR yaitu OTDR mengirimkan pulsa pendek berupa cahaya (antara $5 \mu \mathrm{s} s / \mathrm{d} 20 \mu \mathrm{s}$ ) pulsa yang semakin lebar bisa mengukur fiber optik yang lebih panjang tetapi dengan resolusi yang rendah, pulsa yang lebih sempit bisa mengukur dengan resolusi yang lebih tinggi tetapi hanya falid untuk jarak pengukuran optik yang lebih pendek. Fault Location seperti letaknya serat optik atau sambungan dapat terjadi pada saat instalasi atau setelah instalasi, OTDR dapat menunjukan lokasi faultnya atau ketidaknormalan tersebut.

Penelitian ini adalah penelitian analisis, yaitu dengan menganalisis nilai redaman total tiap core pada site-site yang diteliti pada jaringan FTTH di PT Telkom Makassar. Adapun datadata yang dibutuhkan pada penelitian ini adalah:

- Data redaman standar dan redaman total pada jaringan FTTH.

- Jenis topologi yang digunakan pada site-site dalam penelitian

- Hasil dari nilai redaman serta panjang kabel pada tiap core di site-site pada jaringan FTTH.

Teknik pengolahan data dilakukan dengan melakukan perhitungan redaman total berdasarkan karakteristik sistem yang digunakan. Berdasarkan hal tersebut, maka dapat disimpulkan bahwa perhitungan jarak kabel fiber yang digunakan pada site yang diteliti menggunakan alat Optical Time Domain Reflection (OTDR). Adapun perhitungan redaman total dengan dapat dihitung dengan munggunakan rumus:

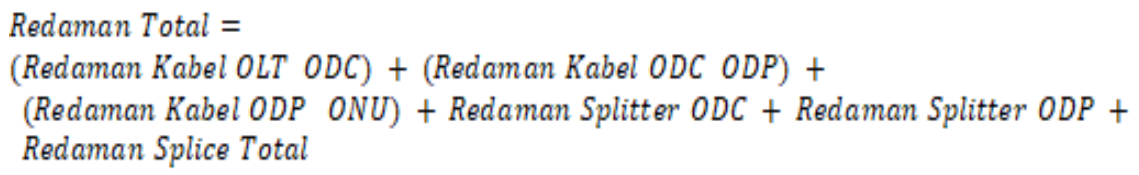

\section{Hasil dan diskusi}

Pada bab ini akan dibahas mengenai gangguan, penyebab serta solusi dan penyelesaian gangguan di PT Telkom Makassar dengan menggunakan metode pemantauan terhadap level batas wajar dari redaman yang diduga penyebab terjadinya gangguan pada jaringan FTTH. Kemudian mengukur redaman, apakah nilai redaman melewati level batas 
wajar, kemudian hasil tersebut dibandingkan dengan hasil penelitian di lapangan dengan data yang ada pada PT Telkom Makassar.

\subsection{Perhitungan Redaman}

Perhitungan redaman untuk jaringan ini dibutuhkan, karena dengan didapatnya redaman yang sesuai dengan batas wajar yang telah ditentukan yaitu 15-28 dB maka jaringan tersebut bisa dikatakan baik atau tidak akan terjadi gangguan secara teknikal transmisi.

Untuk perhitungan ini dibutuhkannya analisis penentuan splitter karena redaman splitter yang dihasilkan sangat mempengaruhi perhitungan redaman ini. Perhitungan redaman pada penelitian ini mengambil 3 contoh site yang setiap site menggunakan splitter 1:8 pada ODC dan splitter 1:4 pada ODP. yang digunakan untuk menghitung redaman total

Tabel 1. Ketentuan standar redaman dan redaman total PT Telkom Makassar

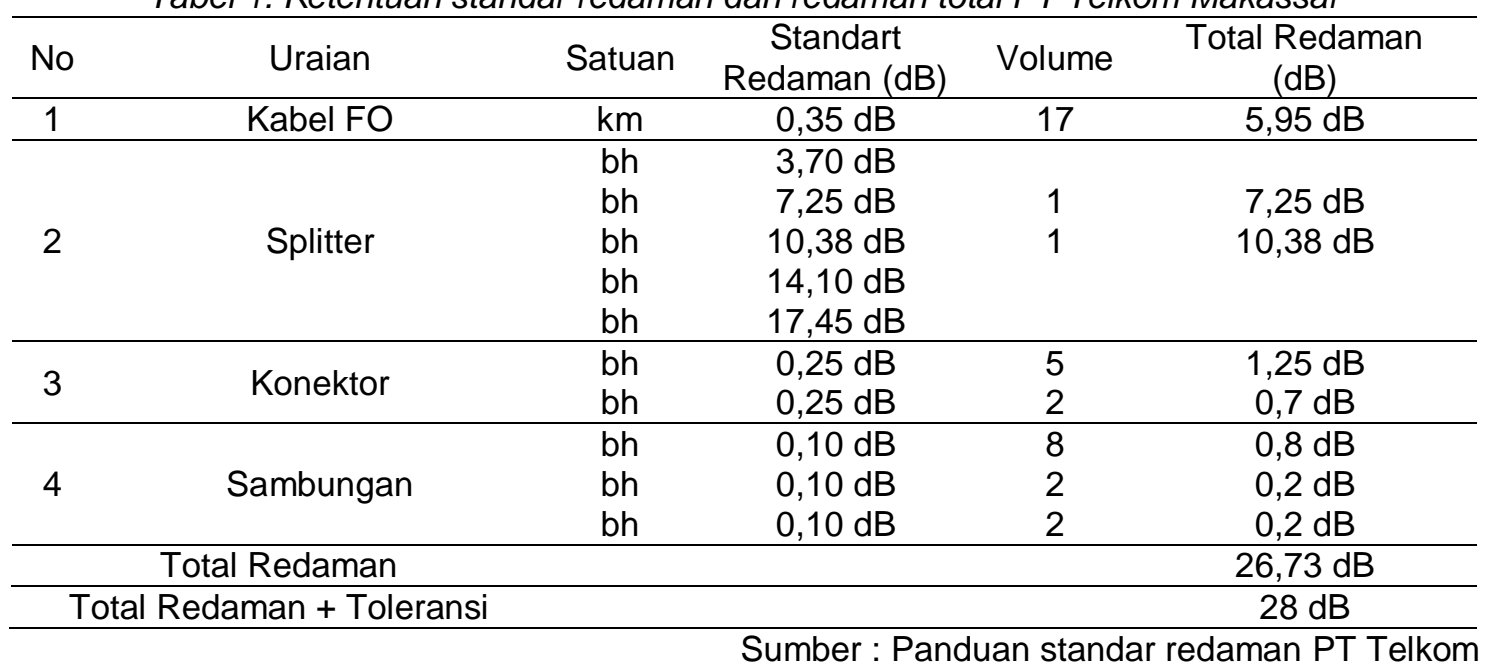

Keterangan :

Redaman Range $\quad=15-28 \mathrm{~dB}$

Redaman Kabel $\quad=0,35 \mathrm{~dB}$

Redaman Splitter 1:4 $=7,25 \mathrm{~dB}$

Redaman Splitter 1:8 $=10,38 \mathrm{~dB}$

\subsection{Data dan Perhitungan Redaman Total}

Perhitungan kabel fiber optik dimulai dari OLT yang berada pada STO, lalu terhubung ke ODC yang berada di site Karunrung kemudian terhubung ke ODP yang berada pada site ODP yang langsung tehubung ke ONU yang terpasang pada rumah pengguna jaringan FTTH. Gambar 1 menunjukkan denah pada site Karunrung.

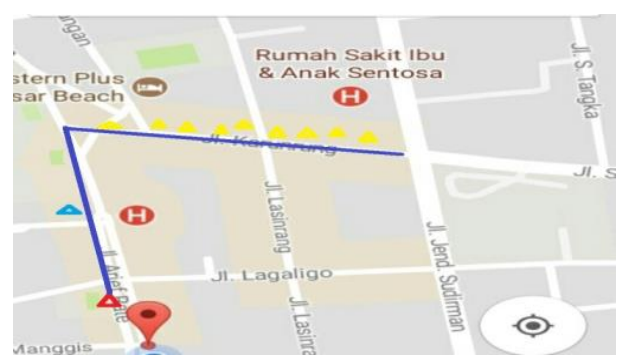

Gambar 1. Denah site Karunrung

Keterangan:

$\triangle$ = Rumah pengguna

$\triangle=$ ODP

$\triangle=$ ODC

$\underline{\boldsymbol{r}}=$ Jalur Kabel Fiber Optik 


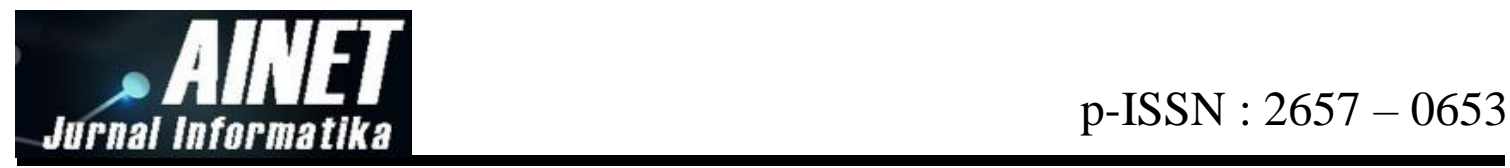

Hasil perhitungan pada site Karunrung menggunakan alat OTDR ditunjukkan pada gambar 2.

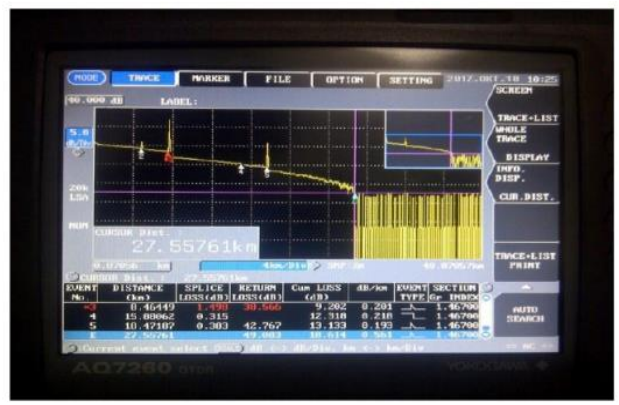

Gambar 2. Hasil perhitungan OTDR site Karunrung

Perhitungan redaman untuk site Karunrung:

Redaman Kabel OLT-ODC

Panjang Kabel x Redaman Kabel OLT-ODC Redaman Kabel ODC-ODP

Panjang Kabel x Redaman Kabel ODC-ODP $=3 \mathrm{~km} \times 0,35 \mathrm{~dB}=1,05 \mathrm{~dB}$

Redaman Kabel ODP-ONU

Panjang Kabel x Redaman Kabel ODP-ONU

Redaman Splitter ODC

$=3 \mathrm{~km} \times 0,35 \mathrm{~dB}=1,05 \mathrm{~dB}$

Redaman Splitter ODP

$=2 \mathrm{~km} \times 0,35 \mathrm{~dB}=0,7 \quad \mathrm{~dB}$

$=7,25 \mathrm{~dB}$

Redaman Splice total

$=10,38 \mathrm{~dB}$

$=1,5 \quad \mathrm{~dB}$

Redaman TOTAL pada site Karunrung

$=21,23 \mathrm{~dB}$

Sesuai dengan range yang ditentukan yaitu $15-28 \mathrm{~dB}$

Perhitungan kabel fiber optik pada site Sungai Saddang dimulai dari OLT yang berada pada STO, lalu terhubung ke ODC yang berada di site Sungai Saddang kemudian terhubung ke ODP yang berada pada site ODP yang langsung tehubung ke ONU yang terpasang pada rumah pengguna jaringan FTTH. Gambar 3 menunjukkan denah pada site Sungai Saddang.

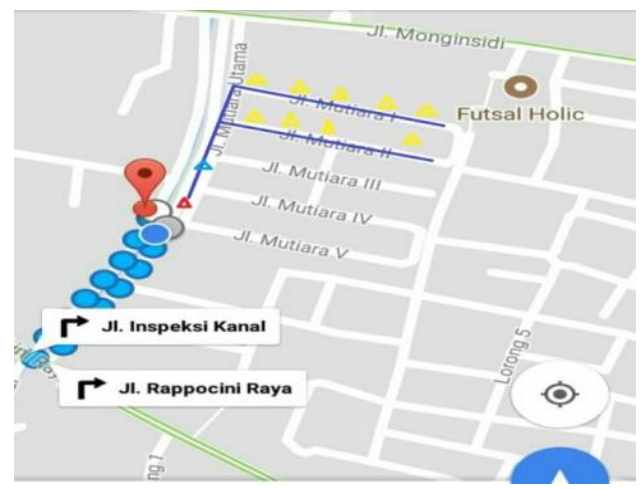

Gambar 3. Denah site Sungai Saddang

Hasil perhitungan pada site Sungai Saddang menggunakan alat OTDR ditunjukkan pada gambar 4. 


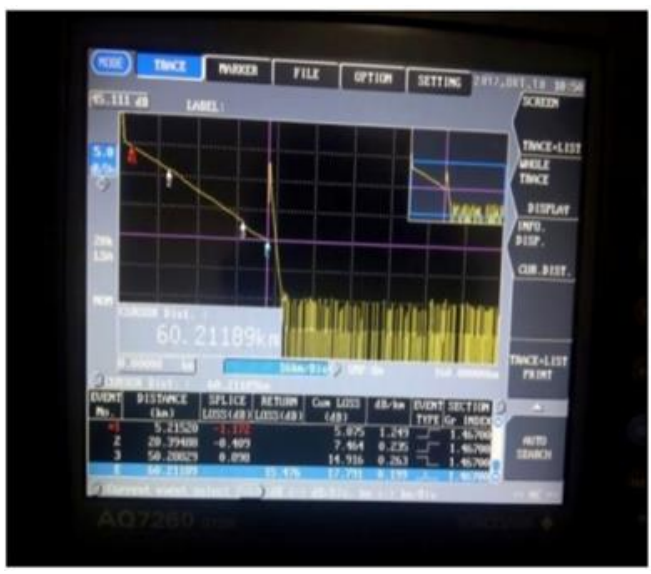

Gambar 4. Hasil perhitungan OTDR site Sungai Saddang

Perhitungan redaman untuk site Sungai Saddang:

Redaman Kabel OLT-ODC

Panjang Kabel $\times$ Redaman Kabel OLT-ODC $\quad=2 \mathrm{~km} \times 0,35 \mathrm{~dB}=0,7 \quad \mathrm{~dB}$

Redaman Kabel ODC-ODP

Panjang Kabel $\times$ Redaman Kabel ODC-ODP $=2 \mathrm{~km} \times 0,35 \mathrm{~dB}=0,7 \quad \mathrm{~dB}$

Redaman Kabel ODP-ONU

Panjang Kabel $x$ Redaman Kabel ODP-ONU $\quad=1 \mathrm{~km} \times 0,35 \mathrm{~dB}=0,35 \mathrm{~dB}$

Redaman Splitter ODC

Redaman Splitter ODP

$=7,25 \mathrm{~dB}$

Redaman Splice total

$=10,38 \mathrm{~dB}$

$=1,2 \mathrm{~dB}$

Redaman TOTAL pada site Sungai Saddang

Sesuai dengan range yang ditentukan yaitu $15-28 \mathrm{~dB}$

$=20,58 \mathrm{~dB}$

Perhitungan kabel fiber optik untuk Taman Sudiang dimulai dari OLT yang berada pada STO, lalu terhubung ke ODC yang berada di site Taman Sudiang kemudian terhubung ke ODP yang berada pada site ODP yang langsung tehubung ke ONU yang terpasang pada rumah pengguna jaringan FTTH. Gambar 5 menunjukkan denah pada site Taman Sudiang.

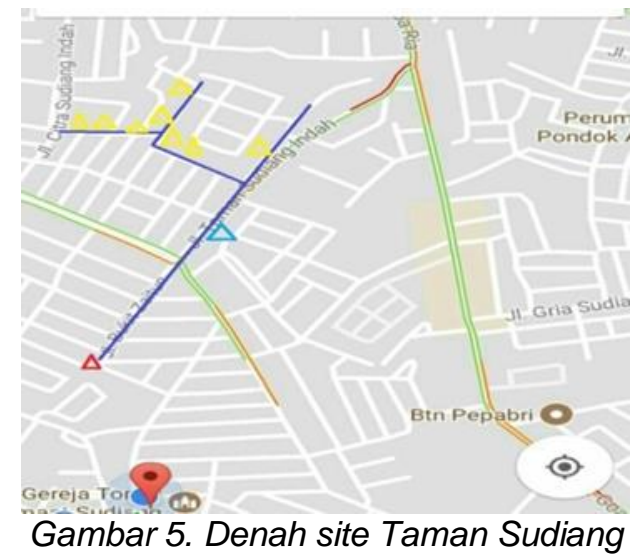
gambar 6 .

Hasil perhitungan pada site Taman Sudiang menggunakan alat OTDR ditunjukkan pada 


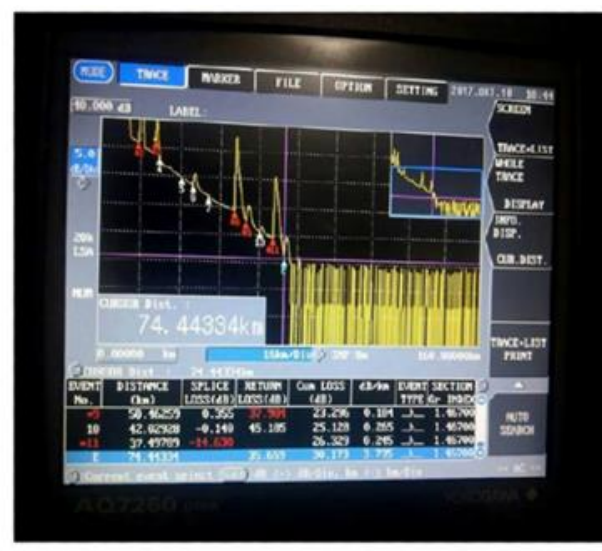

Gambar 6. Hasil perhitungan OTDR site Taman Sudiang

Perhitungan redaman untuk site Taman Sudiang:

Redaman Kabel OLT-ODC

Panjang Kabel x Redaman Kabel OLT-ODC

Redaman Kabel ODC-ODP

Panjang Kabel x Redaman Kabel ODC-ODP

Redaman Kabel ODP-ONU

Panjang Kabel x Redaman Kabel ODP-ONU

Redaman Splitter ODC

Redaman Splitter ODP

$=20 \mathrm{~km} \times 0,35 \mathrm{~dB}=7 \quad \mathrm{~dB}$

$=16 \mathrm{~km} \times 0,35 \mathrm{~dB}=5,6 \quad \mathrm{~dB}$

$=14 \mathrm{~km} \times 0,35 \mathrm{~dB}=4,9 \quad \mathrm{~dB}$

$=7,25 \mathrm{~dB}$

$=10,38 \mathrm{~dB}$

Redaman Splice total

$=0,3 \quad \mathrm{~dB}$

Redaman TOTAL pada site Sungai Saddang

Sesuai dengan range yang ditentukan yaitu $15-28 \mathrm{~dB}$

$=35,43 \mathrm{~dB}$

Tabel 2. Hasil pengamatan redaman tiap site

\begin{tabular}{ccccc}
\hline \multirow{2}{*}{ Site } & \multicolumn{5}{c}{ Keterangan } \\
\cline { 2 - 5 } & $\begin{array}{c}\text { Panjang Kabel } \\
\text { Keseluruhan }(\mathrm{km})\end{array}$ & $\begin{array}{c}\text { Jarak Lokasi } \\
\text { Kejadian }(\mathrm{km})\end{array}$ & $\begin{array}{c}\text { Redaman Kabel } \\
\text { OLT-ODC }(\mathrm{dB})\end{array}$ & $\begin{array}{c}\text { Redaman Kabel } \\
\text { ODC-ODP }(\mathrm{dB})\end{array}$ \\
\hline Site Karunrung & 27,55761 & 8,46449 & 1,05 & 1,05 \\
\hline $\begin{array}{c}\text { Site Sungai } \\
\text { Saddang }\end{array}$ & 60,21189 & 5,21520 & 0,7 & 0,7 \\
\hline $\begin{array}{c}\text { Site Taman } \\
\text { Sudiang }\end{array}$ & 74,44334 & 50,46259 & 7 & 5,6 \\
\hline & \multicolumn{3}{c}{ Sumber: Hasil penelitian redaman total }
\end{tabular}

Dari tabel 2 dapat dilihat bahwa secara umum besarnya redaman total dipengaruhi oleh panjang kabel optik. Akan tetapi ada faktor lain yang mempengaruhi besarnya redaman total yaitu banyaknya jumlah sambungan dan besarnya redaman per kilometer untuk tiap kabel.

OTDR dipakai untuk memastikan loss sambungan, konektor dan loss karena tekukan atau tekanan terhadap kabel. Sebagai contoh pada site Taman Sudiang. Nilai redaman melewati batas range yang ditentukan yaitu 15-28 dB. Faktor yang mempengaruhi besarnya nilai redaman pada site tersebut yaitu jarak yang terlalu jauh atau banyaknya sambungan yang terdapat pada jalur kabel fiber optik yang dilewati pada site taman Sudiang. Cara yang dapat digunakan untuk mengurangi besarnya redaman total adalah dengan mengganti kabel dengan redaman $0,22 \mathrm{~dB} / \mathrm{km}$, maka yang terjadi adalah: 


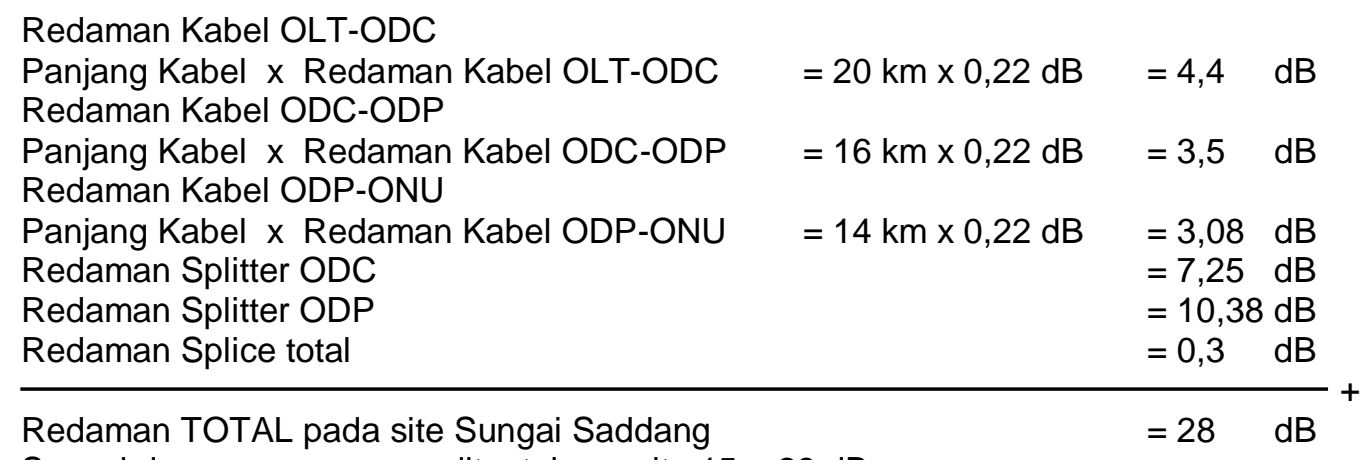

Sesuai dengan range yang ditentukan yaitu $15-28 \mathrm{~dB}$

Setelah dilakukan perhitungan redaman total pada site taman Sudiang dengan menggunakan kabel dengan redaman 0,22 dB terlihat terjadi perubahan nilai redaman total. Dari redaman total $35,43 \mathrm{~dB}$ pada saat menggunakan kabel dengan redaman $0,35 \mathrm{~dB} / \mathrm{km}$ menjadi $28 \mathrm{~dB}$ pada saat menggunakan kabel dengan redaman 0,22 dB.

\section{Kesimpulan}

Berdasarkan hasil penelitian yang dilakukan dapat disimpulkan bahwa penyebab terjadinya peningkatan nilai redaman kabel fiber optik adalah banyaknya splice/sambungan pada setiap kabel, dan terjadinya lekukan kabel di atas $45^{\circ}$. Hasil perhitungan redaman total wilayah makassar seperti site Karunrung diperoleh redaman total 21,23 dB, pada site Sungai Saddang diperoleh redaman total $24,74 \mathrm{~dB}$ dan pada site Taman Sudiang diperoleh redaman total 35,45 dB. Hasil redaman total pada site Taman Sudiang telah melewati batas wajar sehingga dilakukan penggantian kabel fiber optik dari kabel fiber optik dengan redaman 0,35 dB menjadi kabel fiber optik dengan redaman 0,22 dB.

\section{Referensi}

[1] G. Fazar, D. Praja, and L. L. Aryanta, "Analisis Perhitungan dan Pengukuran Transmisi Jaringan Serat Optik Telkomsel Regional Jawa Tengah," J. Reka Elkomika @Teknik Elektro | Itenas J. Online Inst. Teknol. Nas. J. Reka Elkomika, vol. 1, no. 1, pp. 2337-439, 2013.

[2] S. P.Toago, Alamsyah, and A. Amir, "Perancangan Jaringan Fiber To the Home ( Ftth ) Berteknologi Gigabit Passive Optical Network ( Gpon ) Di Perumahan,” pp. 40-46, 2014.

[3] B. Dermawan, I. Santoso, and T. Prakoso, "Analisis Jaringan Ftth (Fiber To the Home) Berteknologi Gpon (Gigabit Passive Optical Network),” vol. 18, no. 1, pp. 30-37, 2016.

[4] N. F. Zamzami and P. Telkom, "Implementasi load balancing dan failover menggunakan mikrotik router os berdasarkan multihomed gateway pada warung internet" diga"," DIGA",", Skripsi. UDINUS Indones., 2013. 